\title{
Performance Evaluation for Competency of Bank Telemarketing Prediction using Data Mining Techniques
}

\author{
Md. Rashid Farooqi, Naiyar Iqbal
}

\begin{abstract}
In today's market there is cut throat competition in the banks and struggling hard to gain competitive advantage over each other. The banking industry has undergone tremendous changes in the way business conducted. They realizes the needs and techniques of data mining which is helpful tool to gather, store, capture data and convert into knowledge. The application of data mining enhances the performance of telemarketing process in banking industry. It also provide an insight how these techniques effectively used in banking industry to make the decision making process easier and productive. This work describes a data mining approach to extract valuable knowledge and information from a bank telemarketing campaign data. At this time, the potential of five data mining methods was explored for forecasting of term deposit subscription. The presentation of these techniques was evaluated on fourteen different classifier parameters. The overall better performance achieved by $\mathrm{J48}$ decision tree which reported $91.2 \%$ correctly classified with sensitivity, specificity and lowest error rate of 53.8, 95.9 and $8.8 \%$ respectively.
\end{abstract}

Keywords: Bank telemarketing, direct marketing, decision support, data mining, classification.

\section{INTRODUCTION}

Telemarketing is one of the powerful means of direct marketing as mobile brought revolution in the field of communication. It is really beneficial for direct marketing at much lower cost. The present era can be described as mobile information society that is why mobile became a household name [4]. The boom in mobile sale and multiple application of it has indeed affected the telemarketing services $[8,9]$.

Telemarketing is one of the important tools of direct marketing. The most successful telemarketing is to rely upon the quality of prospect data. By using data mining technique one may predict the expected customer that have a greater chance to use the services [7,9]. In order to understand the behaviours of customer many commercial banks using

Revised Manuscript Received on 30 July 2019

* Correspondence Author

Md. Rashid Farooqi*, Department of Management Studies, Maulana Azad National Urdu University, Hyderabad, Telangana, India

Naiyar Iqbal, Department of Computer Science and Information Technology, Maulana Azad National Urdu University, Hyderabad, Telangana, India

(C) The Authors. Published by Blue Eyes Intelligence Engineering and Sciences Publication (BEIESP). This is an open access article under the CC-BY-NC-ND license http://creativecommons.org/licenses/by-nc-nd/4.0/ different predictive models based upon the data mining to predict or forecast the customer for segmenting the customer before offering any services by banks [6].

In case of commercial banks and financial institutions decision making becomes ever more critical. There is a large quantity of data, incomplete knowledge and availability of various alternatives increasing complexity in decision making. A good decision support system is very helpful to extract the best alternative. For organization like commercial banks, a computer based information system is very helpful and provide a quick decision.

A well designed decision support system is an interactive software based system a business intelligence system that means to helps support decision maker [10]. It complies and select useful and meaning information form a huge set of raw data, documents, knowledge or business model in order to make concrete decision.

Data mining refers to extracting valuable knowledge from huge amount of data. It is a powerful new technology with great potential to analyze important information from the data warehouse [3,5,12]. Besides, statute of these techniques has been evaluated on various classification performance indicators for forecast of term deposit subscription. For the consideration, five data mining algorithms have been applied namely as J48 decision tree, Sequential minimal optimization, Artificial neural network, Naive bayes and k-nearest neighbour.

\section{OBJECTIVES}

The main objective of the study is to predict the success or effectiveness of telemarketing for banking sector. A commercial Portuguese banking institution was considered. A data mining approach is proposed the competency of telemarketing for selling bank long term deposit.

Therefore many classifier methods can be analyzed with respect to performance. Target of this research additionally incorporates the correlation of various classification techniques with the assistance of charts on the basis of the dataset. All the methods have been measured by the use of WEKA data mining tool.

\section{MATERIAL \& TOOL}

In this research work, bank marketing dataset [8] is used which is available at UCI machine learning repository [1].

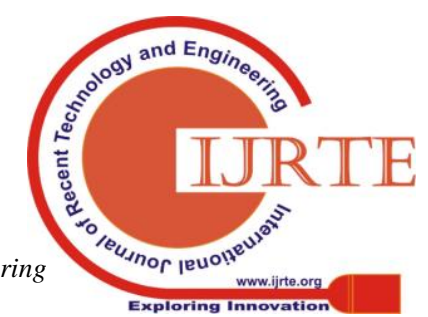


This dataset contains 41188 records with 4640 records with term deposit subscribed (yes) and 36548 records without term deposit subscribed (no). For forecasting of term deposit subscription, 20 distinct attributes have been considered which is tabulated below (table 1).

This dataset was contributed by Portuguese banking institution. Dataset records consisted of total of 41188 records with 20 attributes for each record. Records with presence of term deposit subscription were treated as yes class and records with the absence of term deposit subscription were treated as no class for purpose of analysis. The correlation between twenty attributes of yes and no records shows the high correlation between the attributes of the two classes of samples as stated in Figures 1 and 2.

Chunk was chosen from this dataset which was dealt as training set and tested this dataset on WEKA data mining tool. ARFF is the file format of datasets that is accepted by WEKA data mining tool. WEKA is a well-known set for data mining software coded by JAVA programming, developed at the University of Waikato, New Zealand. Our fundamental concentration is on term deposit subscription that whether a client is subscribed term deposit or not by applying some attributes. On the premise of outcomes, it will demonstrate accuracy of classifiers and then compare on different performance parameters. WEKA is one of the prominent data mining tool for the classification of accuracy measurement by applying the distinctive methods.

\section{DATA MINING TECHNIQUES}

Data mining is the proficient detection of previously obscure, substantial, potential, usable, distinguishable patterns in huge datasets. The investigation of observational data sets to discover unsuspected connections and to condense the data in new ways that are both distinguishable and usable [12].

Data mining phases are as follow:

- Step 1: Problem identification

- Step 2: Formulation hypothesis

- Step 3: Data collection

- Step 4: Data pre-process

- Step 5: Model estimation

- Step 6: Model Interpret and draw conjecture

\section{METHODOLOGY}

In this research study, five prominent data mining techniques have been used for predicting client term deposit subscription. These forecasts have been accomplished for the goal of classification and accuracy by applying diverse data mining methods. The edge used for this objective in paper is Explorer Interface. Explorer Interface is the strand applied for this purpose in research work. Accuracy can be seen by choosing the accompanying data mining techniques: DT, SMO, ANN, $\mathrm{NB}$ and $\mathrm{k}-\mathrm{NN}$.

\begin{tabular}{|l|l|l|}
\hline Attribute Name & Data type & Remark \\
\hline 1. Age & Numeric & age of client \\
\hline 2. Job & Categorical & type of job \\
\hline 3. Marital & Categorical & marital status \\
\hline 4. Education & Categorical & has credit in default? \\
\hline 5. Default & Categorical & has credit in default? \\
\hline 6. Housing & Categorical & has housing loan? \\
\hline
\end{tabular}

\begin{tabular}{|c|c|c|}
\hline 7. Loan & Categorical & has personal loan? \\
\hline 8. Contact & Categorical & contact communication type \\
\hline 9. Month & Categorical & last contact month of year \\
\hline 10. Day of Week & Categorical & last contact day of the week \\
\hline 11. Duration & Numeric & $\begin{array}{ll}\text { last contact duration, (in } \\
\text { seconds) }\end{array}$ \\
\hline 12. Campaign & Numeric & $\begin{array}{l}\text { number of contacts performed } \\
\text { during this campaign and for } \\
\text { this client }\end{array}$ \\
\hline 13. pdays & Numeric & $\begin{array}{l}\text { number of days that passed by } \\
\text { after the client was last } \\
\text { contacted from a previous } \\
\text { campaign }\end{array}$ \\
\hline 14. Previous & Numeric & $\begin{array}{l}\text { number of contacts performed } \\
\text { before this campaign and for } \\
\text { this client }\end{array}$ \\
\hline 15. Poutcome & Categorical & $\begin{array}{l}\text { outcome of the previous } \\
\text { marketing campaign }\end{array}$ \\
\hline 16. Emp_Var_Rate & Numeric & $\begin{array}{l}\text { employment variation rate } \\
\text { quarterly } \\
\text { indicator }\end{array}$ \\
\hline 17. cons_price_idx & Numeric & $\begin{array}{l}\text { consumer price index monthly } \\
\text { indicator }\end{array}$ \\
\hline 18. cons_conf_idx & Numeric & $\begin{array}{l}\text { consumer confidence index } \\
\text { monthly } \\
\text { indicator }\end{array}$ \\
\hline 19. euribor3m & Numeric & euribor 3 month rate \\
\hline 20. nr_employed & Numeric & $\begin{array}{l}\text { number of employees } \\
\text { quarterly } \\
\text { indicator }\end{array}$ \\
\hline y (desired target) & Binary & $\begin{array}{l}\text { has the client subscribed a } \\
\text { term deposit? (Yes/No) }\end{array}$ \\
\hline
\end{tabular}

\subsection{Decision Tree}

Decision tree is a tree like model that describes the data in hierarchy based by each node, and branch has a explicit coexisting with result. Selection of root of tree is appointed commonly through information gain, entropy and gain calculation $[7,8]$.

Attribute selection measure by information gain is described as:

$$
I(p, n)=-\frac{p}{p+n} \log _{2} \frac{p}{p+n}-\frac{n}{p+n} \log _{2} \frac{n}{p+n}
$$

The entropy or requisite information required to classification of objects in overall sub-trees is calculated as:

$$
\text { Entropy }(A)=\sum_{i=1}^{w} \frac{p_{i}+n_{i}}{p+n} I\left(p_{i}+n_{i}\right)
$$

The encoded information can be achieved by branching on A:

$$
\operatorname{Gain}(A)=I(p, n)-E(A)
$$

Here A is Attribute, I is Information gain, $\mathrm{p}$ and $\mathrm{n}$ are element of class $\mathrm{P}$ and $\mathrm{N}$ respectively [2].

In this experiment, the dataset is analyzed on WEKA data mining tool with J48 model and its outcomes is illuminated in the (Figure 4, Table 4). 


\section{Positive Corelation}

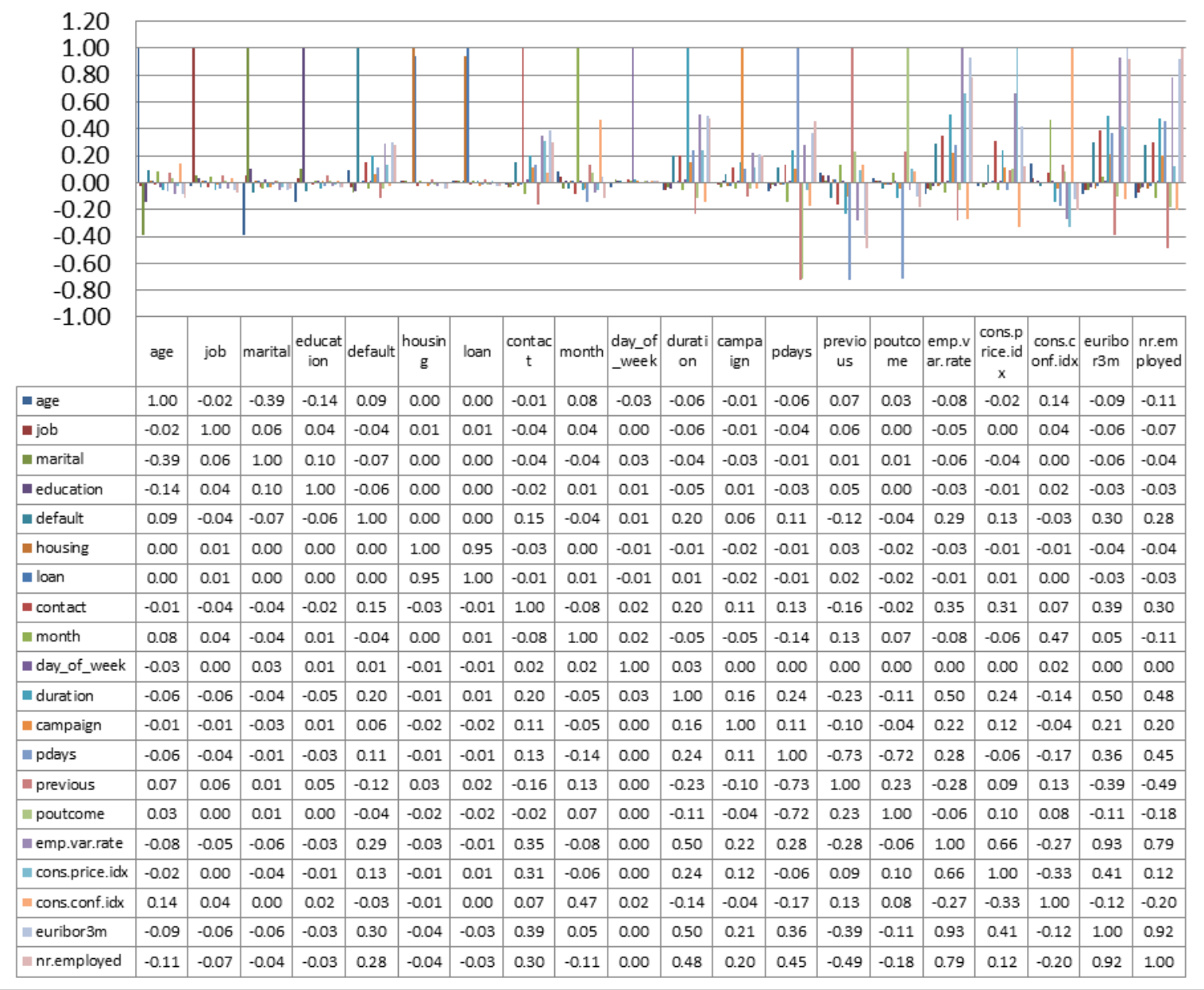

Figure 1: Linear positive correlation

\subsection{Sequential Minimal Optimization}

Sequential minimal optimization is a model for solving the quadratic programming problem which arises at the training time of Support Vector Machine (SVM). SMO is extensively applied for training of SVM [13]. This model is applied for dividing the data based on dataset. After processing this model the outcome of classifier can be estimated by modified estimations to make forecast for every single event of bank advertising dataset. In this experiment, the dataset is analyzed on WEKA data mining tool with SMO model [11] and its outcomes is illuminated in the (Figure 5, Table 5).

\subsection{Artificial Neural Network}

Artificial neural network (ANN) methods effort to influence the arrangement and functions of biological networks of neurons. Fundamental development of every ANN is artificial neuron, to be appropriate and a basic numerical capacity [8,13]. Summation, multiplication and then activation functions are the three basic principles of the ANN model. At the time of initial processing of artificial neuron, the inputs are weight value and which that each input value is multiply different weight. At the time of internal processing, the summation function sums every weight bias and input values. And then at the time of outcome of artificial neuron, the sum of previous weighted inputs and bias is gone via activation function $[2,3]$.

Artificial neuron calculates the output $y_{k}$ as a prescribed function of net ${ }_{k}$ value:

$$
y_{k}=f\left(\text { net }_{k}\right)
$$

here $\mathrm{x}$ and $\mathrm{y}$ are input and output signals respectively, $\mathrm{w}_{\mathrm{kj}}$ is synaptic weight, $\mathrm{j}$ is synapse and $\mathrm{f}$ is activation function.

In this experiment, the dataset is analyzed on WEKA data mining tool with MLP (Multilayer Perceptron) model and its outcomes is illuminated in the (Figure 6, Table 6). 


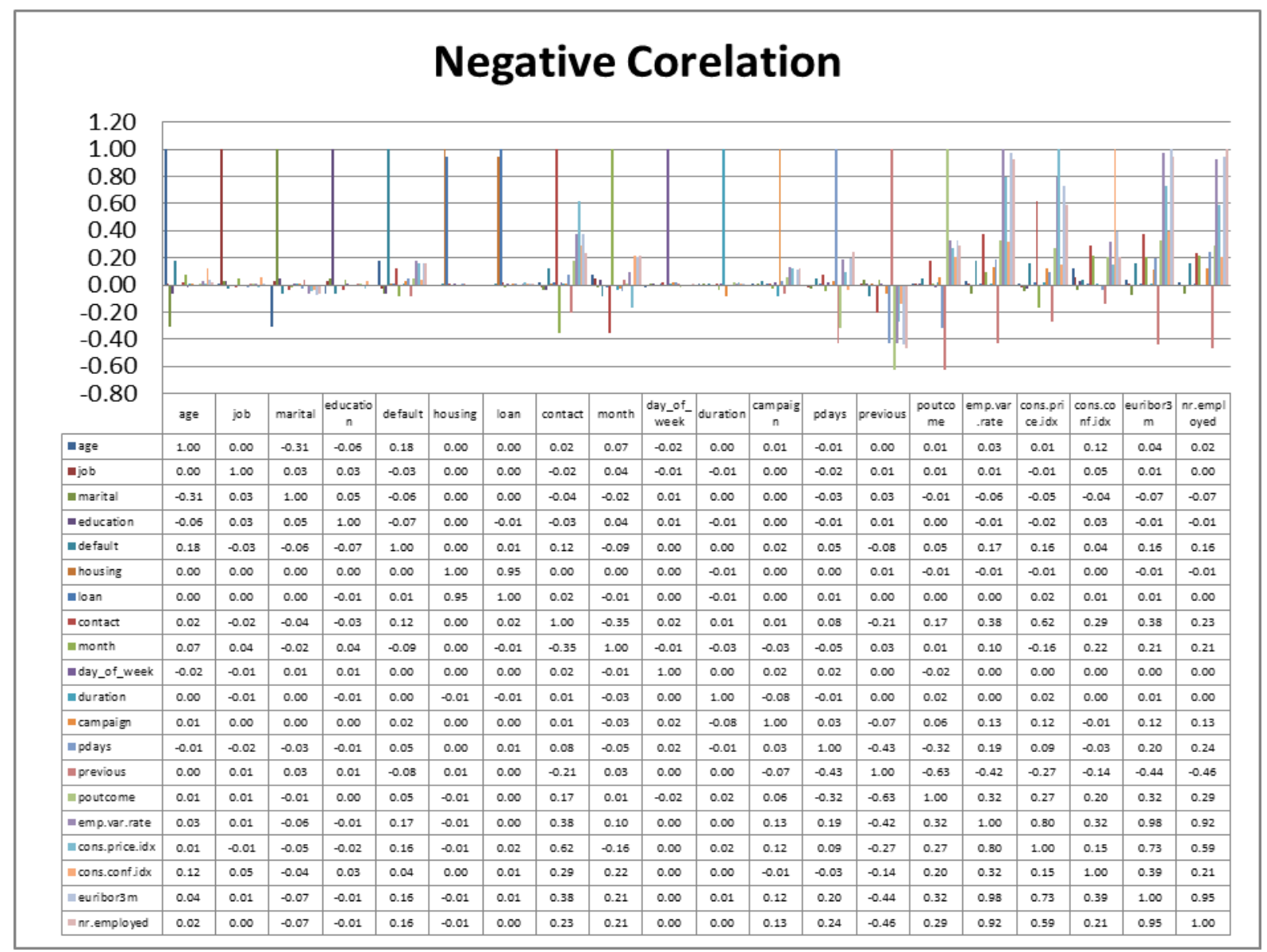

Figure 2: Linear negative correlation

\subsection{Naive Bayes}

Naive Bayes performs arithmetical prediction, such as predicts class participation possibility. A basic Naive Bayes classification model guarantees analogical performance with decision tree and selected neural network classification models [2,13].

Mathematical formulae for Bayes theorem is described as:

$$
P(X \mid Y)=\frac{P(X) P(Y \mid X)}{P(Y)}
$$

here $\mathrm{X}$ and $\mathrm{Y}$ shows as events, $\mathrm{P}(\mathrm{X})$ and $\mathrm{P}(\mathrm{Y})$ indicates the probabilities of $\mathrm{X}$ and $\mathrm{Y}$ without regard to each other. $\mathrm{P}(\mathrm{X} \mid \mathrm{Y})$ is a conditional probability of observing event $\mathrm{X}$ given that $\mathrm{Y}$ is true. $\mathrm{P}(\mathrm{Y} \mid \mathrm{X})$ is the probability of observing event $\mathrm{Y}$ given that $\mathrm{X}$ is true.

In this experiment, the dataset is analyzed on WEKA data mining tool with NB model and its outcomes is illuminated in the (Figure 7, Table 7).

\section{5 k-nearest Neighbour}

k-nearest Neighbour classification model is an instance learning based approach that is influenced to the lazy learning method. Instance based, also familiar as memory-based learning method that matches new problem instances with previously picked instances at training, that is stored in the memory. In k-NN classification, the result is a class membership. The object classification is decided based on majority vote of its neighbour [13].

In this experiment, the dataset is analyzed on WEKA data mining tool with kNN model and its outcomes is illuminated in the (Figure 8, Table 8).

\section{CLASSIFICATION PERFORMANCE MEASUREMENTS}

Confusion matrix, alternatively known as error matrix, is a table representation that is frequently applied to depict classification model performance based on the test dataset for which the true values are known with arrangements of actual and predicted sides. There are various quality parameters such as correctly classified, incorrectly classified, specificity, sensitivity, precision, error rate, ROC and F1 measure described (table 2) for the performance measurements on the confusion matrix.

\section{RESULTS \& COMPARISION}

The performance measurement of subscription of term deposit prediction by five data mining algorithms is evaluated based on 20 attributes as mentioned in materials \& tool section. This dataset consists of 41188 records with 4640 records with term deposit subscribed (yes) and 36548 records without term deposit subscribed (no). Bank marketing dataset records were divided in tenfold, each fold was used in testing and rest folds were applied as training throughout cross validation. 


\begin{tabular}{|c|c|c|c|c|}
\hline \multicolumn{5}{|c|}{ Table 1: J48_Decision tree: } \\
\hline & & \multicolumn{2}{|c|}{ Predicted Class } & \multirow{2}{*}{$\begin{array}{l}\text { Total } \\
\text { Actual }\end{array}$} \\
\hline & & Yes & No & \\
\hline \multirow{2}{*}{ 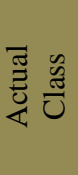 } & Yes & $\begin{array}{c}2498 \\
(62.75 \%)\end{array}$ & $\begin{array}{c}2142 \\
(5.76 \%)\end{array}$ & 4640 \\
\hline & No & $\begin{array}{c}1483 \\
(37.25 \%)\end{array}$ & $\begin{array}{c}35065 \\
(94.24 \%)\end{array}$ & 36548 \\
\hline \multicolumn{2}{|c|}{ Total Predicted } & 3981 & 37207 & 41188 \\
\hline
\end{tabular}

Confusion matrix of prediction result is tabulated (Table 3, Figure 3) for J48 decision tree, and other classifications like, SMO, Artificial neural network, Naive bayes and k-nearest neighbour are shown in Figure 3.

Figure 3 depicts predictions of these machine learning models. It is declared from the results that

Naive Bayes predicts topmost number of true positives (number of records predicted as yes and it does have term deposit subscribed) and SMO predicts topmost number of true negatives (number

of records predicted as no and it doesn't have term deposit subscribed) (Figure 3).

J48 Decision tree confusion matrix shows that it has second highest true positives and also it predicts second highest true negatives (Figure 3).

ANN confusion matrix shows that it has third highest true positives and third highest true negatives (Figure 3).
kNN confusion matrix shows that it has fourth highest true positives and third highest true negatives (Figure 3).

SMO confusion matrix shows worst performer in the sense of lowest true positives and Naive Bayes predicts worst performance in true negatives (Figure 3).

Table 4 to table 8 explains various classification chronicle measurements and Figure 4 to Figure 8 illuminates fourteen classification performance parameters especially correctly classified, incorrectly classified, mean absolute error, root mean squared error, relative absolute error, specificity, sensitivity and precision, FPR, NPV, RMC, ROC, PRC, and F1 measure.

Figure 4 declared that $\mathrm{J} 48$ decision tree outperformed over all other machine learning methods with topmost classification accuracy of $91 \%$ while second highest classification accuracy is achieved by SMO of $90 \%$ (figure 5 , table 5).

On the other hand, Naive Bayes has found highest sensitivity of $61.7 \%$ (figure 7 , table 7 ) and J48 decision tree has got second highest sensitivity of $53.8 \%$ (figure 4 , table 4 ).

Whereas SMO acquires topmost specificity of $98 \%$ (figure 5, table 5) and J48 decision tree has got second highest sensitivity of $95.9 \%$ (figure 4, table 4).

SMO has found highest precision of $65.1 \%$ (figure 5, table 5) and J48 decision tree has got second highest precision of $62.7 \%$ (figure 4 , table 4).

J48 has found lowest RMC of 8.8\% (figure 4, table 4) and SMO has got second lowest RMC of $10.2 \%$ (figure 5, table 5).

The chart undoubtedly shows that J48 decision tree defeats all other methods on F1 score with $58 \%$ (figure 4, table 4). Whereas ANN achieves highest ROC of $89.1 \%$ (figure 6 , table 6 ), and J48 decision tree is the second runner in ROC, that achieve $88.4 \%$ (figure 4 , table 4).

\begin{tabular}{|c|c|c|c|}
\hline True Positive (TP) & True Negative (TN) & False Positive (FP) & False Negative (FN) \\
\hline $\begin{array}{l}\text { Number of client subscribed } \\
\text { term deposit was positive } \\
\text { and predicted right }\end{array}$ & $\begin{array}{l}\text { Number of client subscribed } \\
\text { term deposit was negative and } \\
\text { predicted right }\end{array}$ & $\begin{array}{l}\text { Number of client subscribed } \\
\text { term deposit was negative but } \\
\text { predicted wrong } \\
\text { (Type I error) }\end{array}$ & $\begin{array}{c}\text { Number of client subscribed term deposit was } \\
\text { positive but predicted wrong } \\
\text { (Type II error) }\end{array}$ \\
\hline Measures & Formulae & \multicolumn{2}{|r|}{ Description } \\
\hline Correctly classified & $C A=(T P+T N) f($ total somple $)$ & \multicolumn{2}{|c|}{ Shows percentage of correctly classified records. } \\
\hline Incorrectly classified & $I C=(F P+F M) /($ total sompla $)$ & \multicolumn{2}{|c|}{ Shows percentage of incorrectly classified records. } \\
\hline Mean absolute error & $\sum\left(\| f\left(x_{i}\right)-y_{i} \mid\right) / N$ & \multicolumn{2}{|c|}{ Calculates the mean magnitude of the errors without pondering its leaning. } \\
\hline Root mean squared error & $\left.-y_{i}\right) 2 / N$ & \multicolumn{2}{|c|}{ Calculates the mean magnitude of the error with quadratic calculation principle } \\
\hline Relative absolute error & 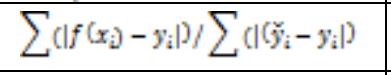 & \multicolumn{2}{|c|}{$\begin{array}{l}\text { computes the entire absolute error and normalized it through dividing by the whole } \\
\text { absolute error }\end{array}$} \\
\hline Sensitivity/Recall/TPR & $T P R=T P /(T P+F N)$ & \multicolumn{2}{|c|}{ Ratio of predicted positive record to the total actually positive records. } \\
\hline Specificity/TNR & $T N R=T N /(T N+F P)$ & \multicolumn{2}{|c|}{ Ratio of predicted negative record to the total actually negative records. } \\
\hline Precision/PPV & $P P V=T P /(T P+F P)$ & \multicolumn{2}{|c|}{ Ratio of predicted positive record to the total predicted positive records. } \\
\hline FPR & $F P R=F P /(F P+T N)$ & \multicolumn{2}{|c|}{ Ratio of predicted positive record to the total actually negative records. } \\
\hline NPV & $N P V=T N /(T N+F N)$ & \multicolumn{2}{|c|}{ Ratio of predicted negative record to the total predicted negative records. } \\
\hline RMC & RUC $=\frac{\text { WyPe \& EFror + Hype aI EFH }}{\text { total sample }}$ & \multicolumn{2}{|c|}{$\begin{array}{l}\text { Ratio of overall incorrectly records to the total number of records (also known as } \\
\text { Error Rate). }\end{array}$} \\
\hline ROC & $\begin{array}{l}\mathrm{X} \text {-axis \& Y-axis plot FPR \& } \\
\text { TPR respectively }\end{array}$ & \multicolumn{2}{|c|}{$\begin{array}{l}\text { ROC curve is a strategy for imagining, sorting out and choosing classifiers in view } \\
\text { of their performance. }\end{array}$} \\
\hline PRC & $\begin{array}{l}\mathrm{X} \text {-axis \& Y-axis plot recall \& } \\
\text { precision respectively }\end{array}$ & \multicolumn{2}{|c|}{$\begin{array}{l}\text { Used as a additional of ROC to obtain the full graphic when assessing and compare } \\
\text { to the tests. }\end{array}$} \\
\hline F1 Measure & $F 1=2 T P /(2 T P+F P+F N)$ & \multicolumn{2}{|c|}{ It is a weighted average of the recall and precision. } \\
\hline
\end{tabular}




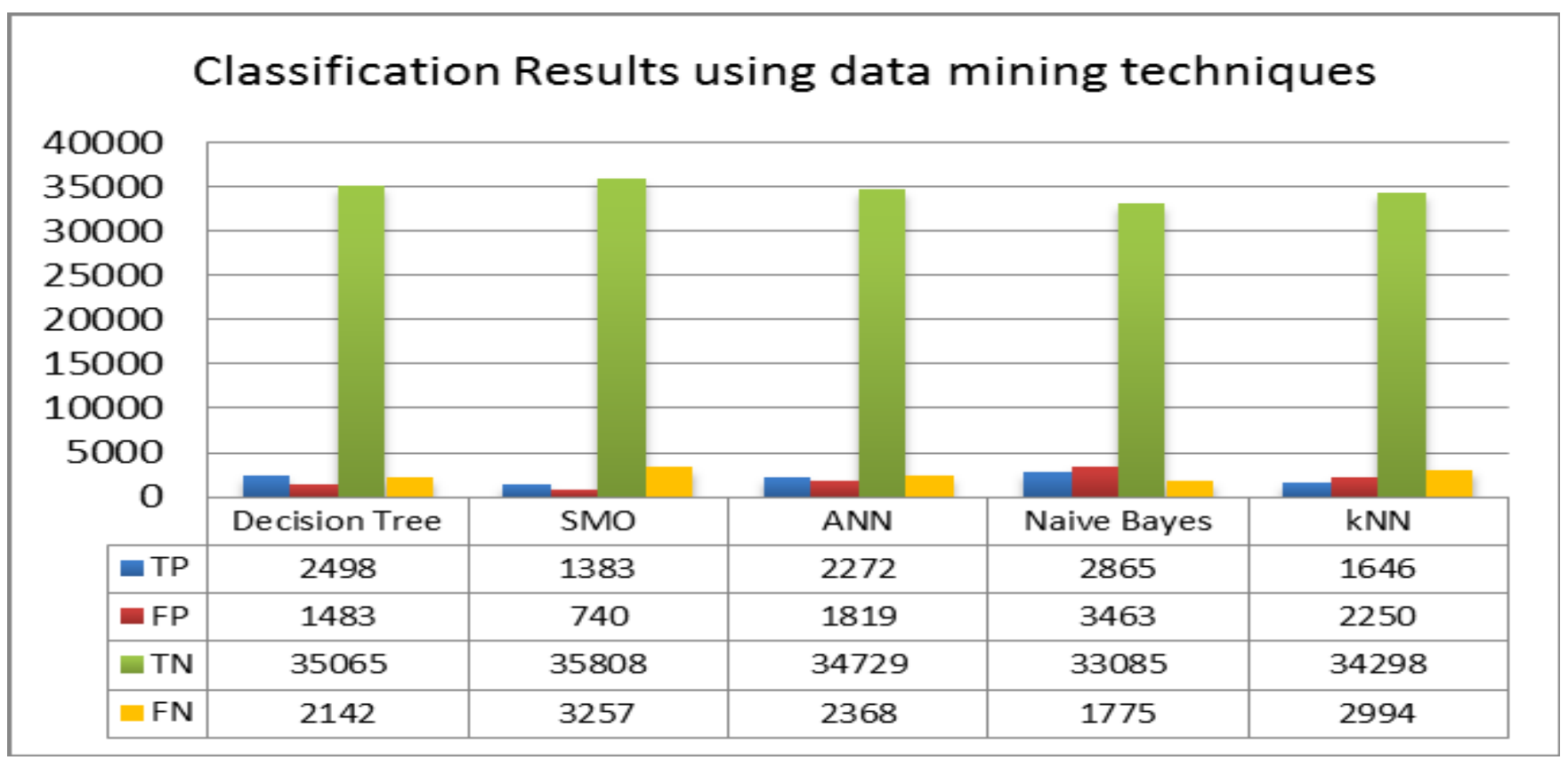

Figure 3: Classification output of data mining techniques.

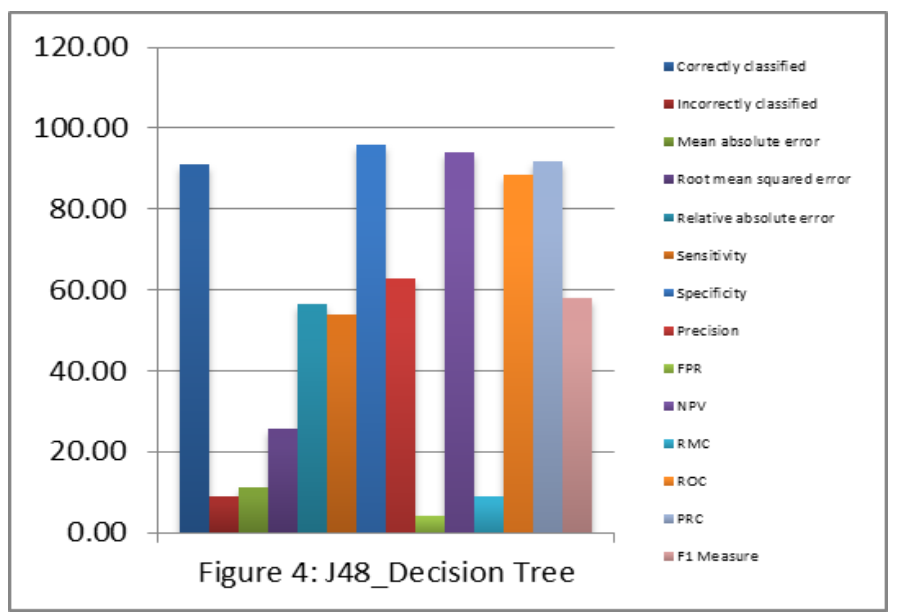

\begin{tabular}{|l|c|}
\hline Measure Parameters & Outcome (\%) \\
\hline Correctly classified & 91.20 \\
\hline Incorrectly classified & 8.80 \\
\hline Mean absolute error & 11.32 \\
\hline Root mean squared error & 25.85 \\
\hline Relative absolute error & 56.62 \\
\hline Sensitivity & 53.8 \\
\hline Specificity & 95.9 \\
\hline Precision & 62.7 \\
\hline FPR & 4.1 \\
\hline NPV & 94.2 \\
\hline RMC & 8.8 \\
\hline ROC & 88.4 \\
\hline PRC & 91.8 \\
\hline F1 Measure & 58 \\
\hline \multicolumn{2}{|c|}{ Table 4: J48_Decision Tree } \\
\hline
\end{tabular}

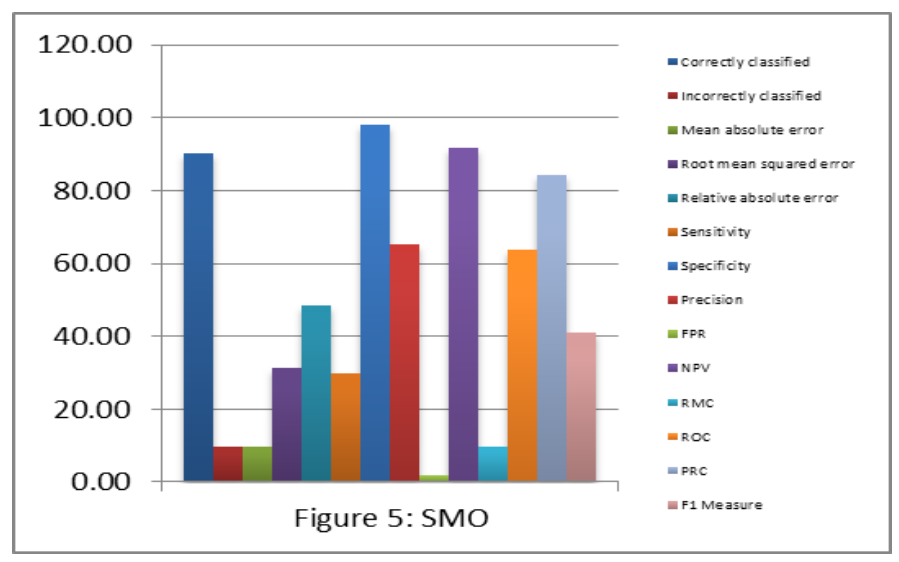

\begin{tabular}{|l|c|}
\hline Measure Parameters & Outcome (\%) \\
\hline Correctly classified & 90.30 \\
\hline Incorrectly classified & 9.70 \\
\hline Mean absolute error & 9.70 \\
\hline Root mean squared error & 31.15 \\
\hline Relative absolute error & 48.54 \\
\hline Sensitivity & 29.8 \\
\hline Specificity & 98 \\
\hline Precision & 65.1 \\
\hline FPR & 2 \\
\hline NPV & 91.7 \\
\hline RMC & 9.7 \\
\hline ROC & 63.9 \\
\hline PRC & 84.4 \\
\hline F1 Measure & 40.9 \\
\hline \multicolumn{2}{|c|}{ Table 5: SMO } \\
\hline
\end{tabular}



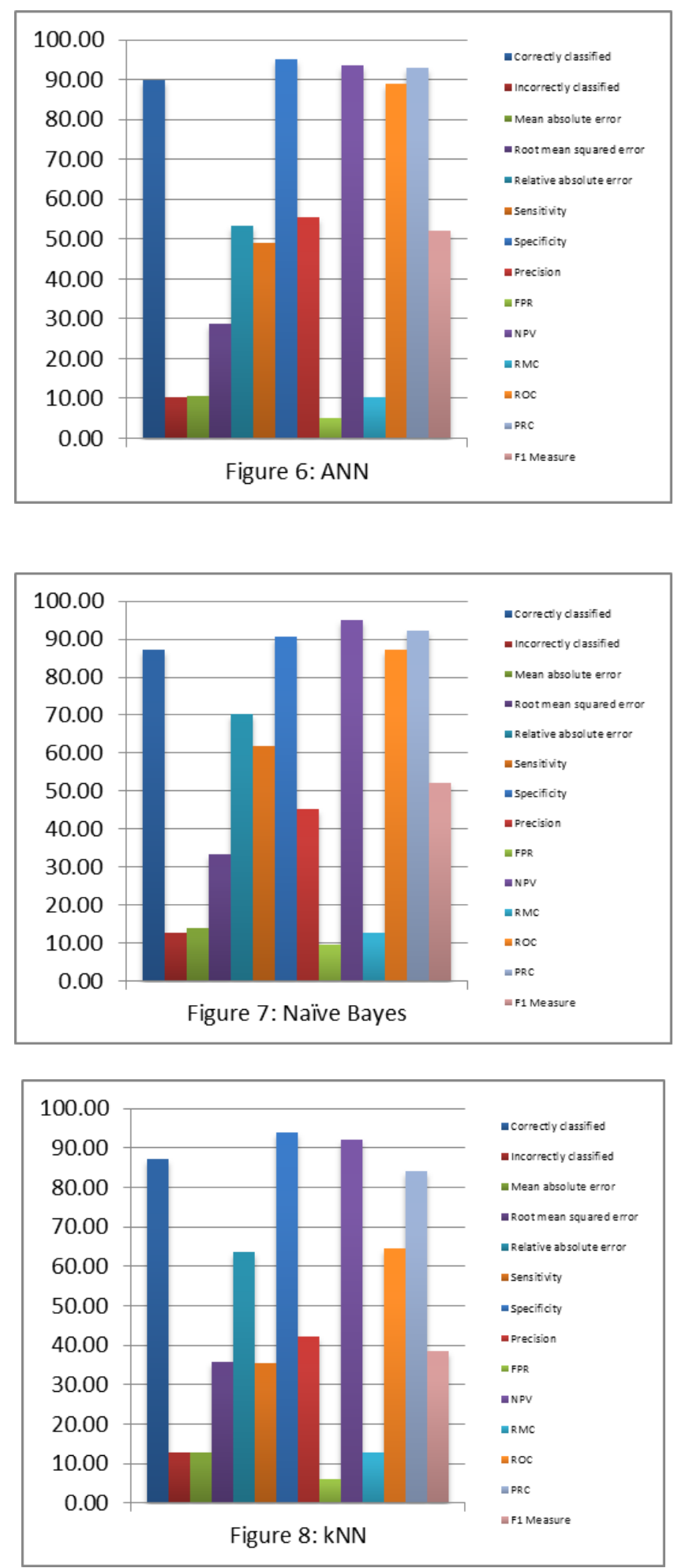

\section{CONCLUSION}

The primary goal of this research study is towards prediction of term deposit subscription using WEKA data mining tool. WEKA has mainly five sections, Explorer, Experimenter, KnowledgeFlow, Workbench and Simple GUI. Out of the five section, Explorer and KnowlegeFlow are used for classification experiment and ROC curve generation for positive and negative class (Figure 10, Figure 11). In this study, five techniques of classification were used i.e. J48 Decision tree, SMO, ANN, NB and kNN. These methods were applied using WEKA data mining software to assess the

\begin{tabular}{|l|c|}
\hline Measure Parameters & Outcome (\%) \\
\hline Correctly classified & 89.83 \\
\hline Incorrectly classified & 10.17 \\
\hline Mean absolute error & 10.66 \\
\hline Root mean squared error & 28.81 \\
\hline Relative absolute error & 53.31 \\
\hline Sensitivity & 49 \\
\hline Specificity & 95 \\
\hline Precision & 55.5 \\
\hline FPR & 5 \\
\hline NPV & 93.6 \\
\hline RMC & 10.2 \\
\hline ROC & 89.1 \\
\hline PRC & 93.1 \\
\hline F1 Measure & 52 \\
\hline \multicolumn{2}{|c|}{ Table } \\
\hline
\end{tabular}

\begin{tabular}{|l|c|}
\hline Measure Parameters & Outcome (\%) \\
\hline Correctly classified & 87.28 \\
\hline Incorrectly classified & 12.72 \\
\hline Mean absolute error & 14.06 \\
\hline Root mean squared error & 33.25 \\
\hline Relative absolute error & 70.30 \\
\hline Sensitivity & 61.7 \\
\hline Specificity & 90.5 \\
\hline Precision & 45.3 \\
\hline FPR & 9.5 \\
\hline NPV & 94.9 \\
\hline RMC & 12.7 \\
\hline ROC & 87.1 \\
\hline PRC & 92.2 \\
\hline F1 Measure & 52.2 \\
\hline \multicolumn{2}{|l|}{ Table 7: Naive Bayes } \\
\hline
\end{tabular}

\begin{tabular}{|l|c|}
\hline Measure Parameters & Outcome (\%) \\
\hline Correctly classified & 87.27 \\
\hline Incorrectly classified & 12.73 \\
\hline Mean absolute error & 12.73 \\
\hline Root mean squared error & 35.68 \\
\hline Relative absolute error & 63.69 \\
\hline Sensitivity & 35.5 \\
\hline Specificity & 93.8 \\
\hline Precision & 42.2 \\
\hline FPR & 6.2 \\
\hline NPV & 92 \\
\hline RMC & 12.7 \\
\hline ROC & 64.5 \\
\hline PRC & 84 \\
\hline F1 Measure & 38.6 \\
\hline \multicolumn{2}{|c|}{ Table $\mathbf{~ k N N}$} \\
\hline
\end{tabular}

classification accuracy that was obtained after experiment of these methods. After experiment through these methods, the results were compared on the base of correctly classified and other performance measures that are described in table 2 .

With the use of Explorer procedure it has concluded that J48 decision tree is the overall leading performance classifier method of data mining in this experiment. J48 decision tree has achieved an accuracy of $91.2 \%$, takes less time to execute and depicts ROC curve $88.4 \%$, and had minimum error rate of $8.8 \%$.

Published By:

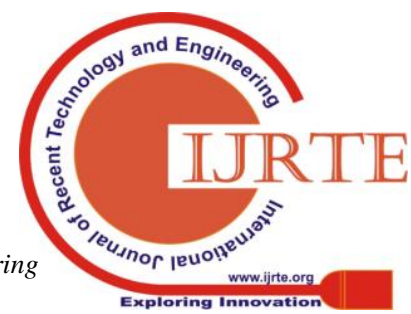




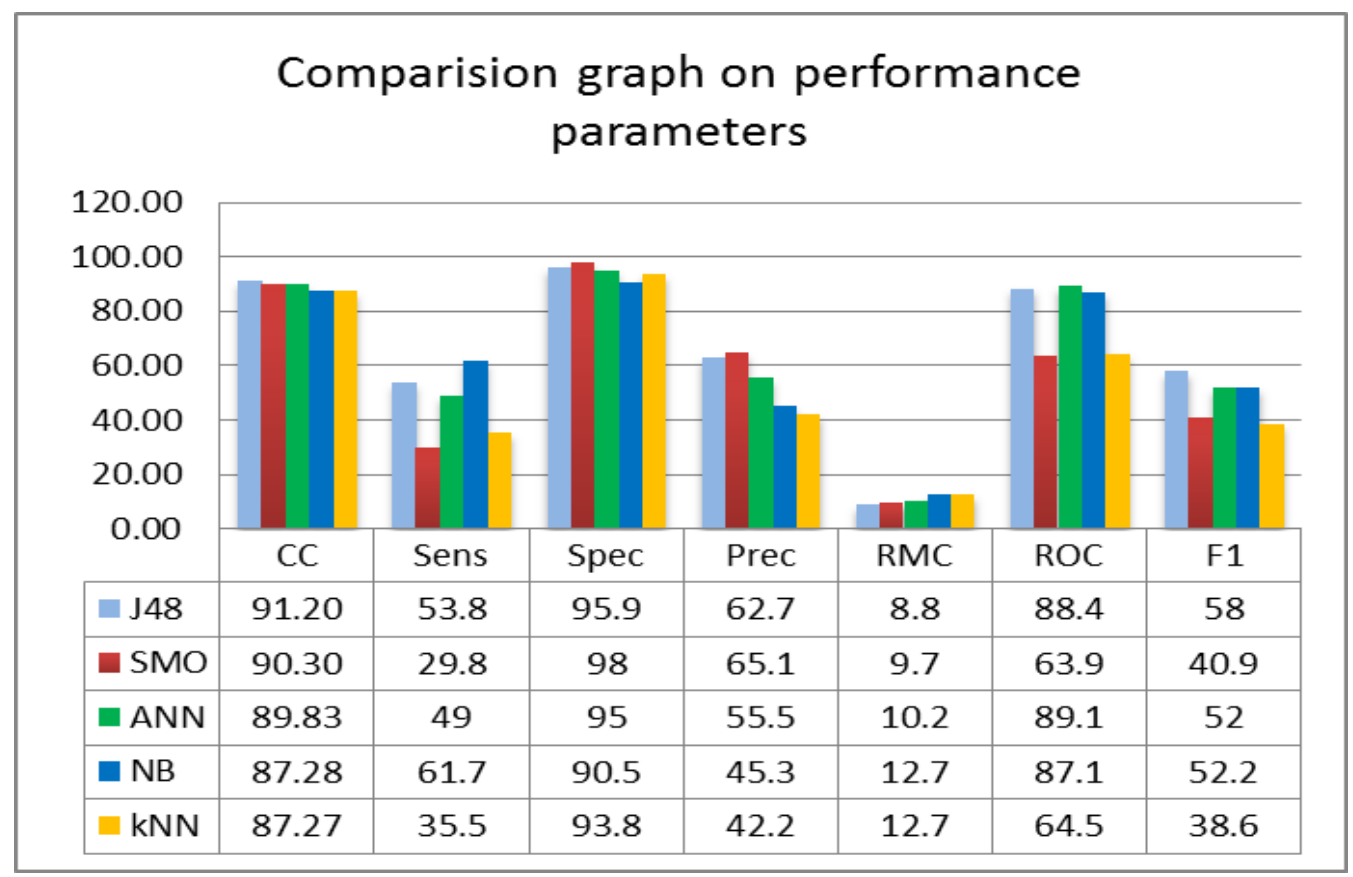

Figure 9: Comparison graph on specific performance parameters for classifier

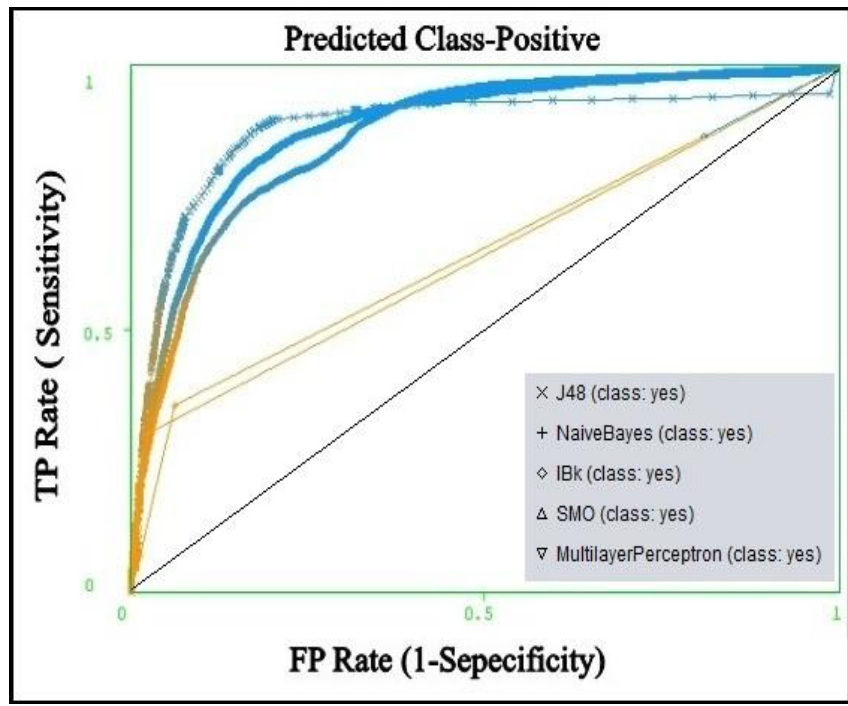

Figure 10: ROC curve for positive class

\section{SCOPE FOR FURTHER RESEARCH}

Apart from marketing data mining can be further used in to extract information form a huge set of data warehouse and enable or leads to a better decision making in the field of banking sector. It can be further use in customer acquisition and retention of customer, the most valuable customers, providing segment base product. It can be also used in fraud detection and risk management.

\section{List of Abbreviation:}

WEKA : Waikato Environment for Knowledge Analysis

ARFF : Attribute Relation File Format

DT : Decision Tree

SVM : Support Vector Machine

SMO : Sequential Minimal Optimization

ANN : Artificial Neural Network

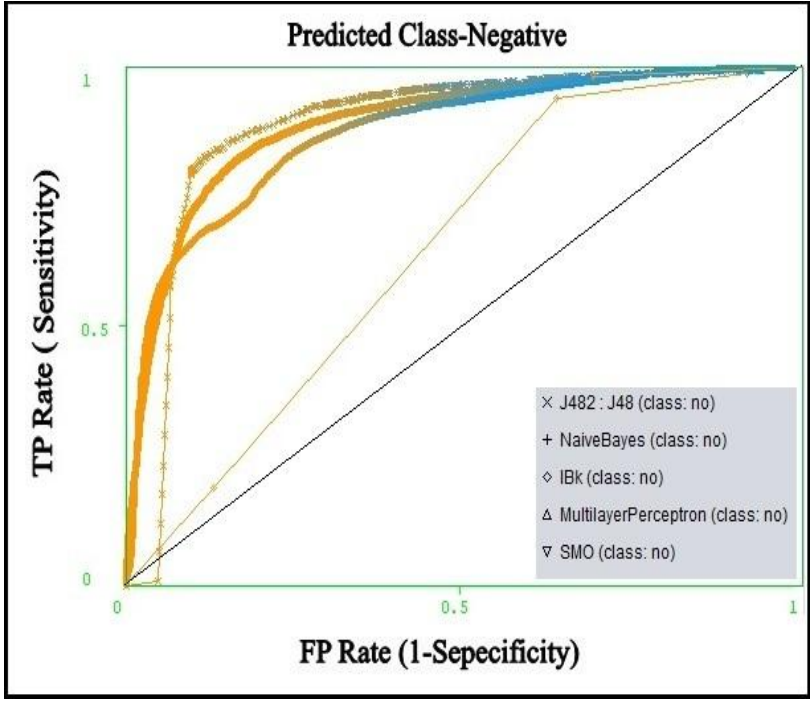

Figure 11: ROC curve for negative class

$\begin{array}{ll}\text { MLP } & \text { : Multilayer Percepton } \\ \text { NB } & \text { : Naive Bayes } \\ \text { kNN } & \text { : k- Nearest Neighbour } \\ \text { CC } & \text { : Correctly Classified } \\ \text { IC } & \text { : Incorrectly Classified } \\ \text { FPR } & \text { : False Positive Rate } \\ \text { NPV } & \text { : Negative Predictive Value } \\ \text { RMC } & \text { : Rate of Misclassification } \\ \text { PRC } & \text { : Precision Recall Curve } \\ \text { ROC } & \text { : Receiver Operative Characteristics }\end{array}$

\section{REFERENCES}

1. Bache, K., \& Lichman, M. (2013). UCI Machine Learning Repository [http://archive. ics. uci. edu/ml]. University of California, School of Information and Computer Science. Irvine, $C A$.

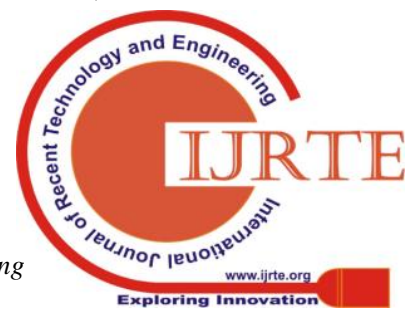


2. Baesens, B., Van Gestel, T., Viaene, S., Stepanova, M., Suykens, J., \& Vanthienen, J. (2003). Benchmarking state-of-the-art classification algorithms for credit scoring. Journal of the operational research society, 54(6), 627-635.

3. Cortez, P. (2010, July). Data mining with neural networks and support vector machines using the R/rminer tool. In Industrial Conference on Data Mining (pp. 572-583). Springer Berlin Heidelberg.

4. Dasgupta, K., Singh, R., Viswanathan, B., Chakraborty, D., Mukherjea, S., Nanavati, A. A., \& Joshi, A. (2008, March). Social ties and their relevance to churn in mobile telecom networks. In Proceedings of the 11th international conference on Extending database technology: Advances in database technology (pp. 668-677). ACM.

5. Hormozi, A. M., \& Giles, S. (2004). Data mining: A competitive weapon for banking and retail industries. Information systems management, 21(2), 62-71.

6. Kotler, P., Keller, K. L., Ancarani, F., \& Costabile, M. (2014). Marketing management 14/e. Pearson.

7. Lessmann, S., Baesens, B., Seow, H. V., \& Thomas, L. C. (2015) Benchmarking state-of-the-art classification algorithms for credit scoring: An update of research. European Journal of Operational Research, 247(1), 124-136.

8. Moro, S., Cortez, P., \& Rita, P. (2014). A data-driven approach to predict the success of bank telemarketing. Decision Support Systems, 62, 22-31.

9. Moro, S., Laureano, R., \& Cortez, P. (2011). Using data mining for bank direct marketing: An application of the crisp-dm methodology. In Proceedings of European Simulation and Modelling Conference-ESM'2011 (pp. 117-121). Eurosis.

10. Olson, D. L., Delen, D., \& Meng, Y. (2012). Comparative analysis of data mining methods for bankruptcy prediction. Decision Support Systems, 52(2), 464-473.

11. Platt, J. (1998). Sequential minimal optimization: A fast algorithm for training support vector machines.

12. Raza, K. (2010). Application of Data Mining in Bioinformatics. Indian Journal of Computer Science \& Engineering (IJCSE), 1(2): 114-118.

13. Raza, K., \& Hasan, A. N. (2015). A comprehensive evaluation of machine learning techniques for cancer class prediction based on microarray data. International journal of bioinformatics research and applications, 11(5), 397-416.

\section{AUTHORS PROFILE}

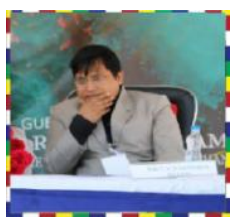

Dr. Md. Rashid Farooqi is currently working as an Assistant Professor at Department of Management, School of Commerce \& Business Management, Maulana Azad National Urdu University (Central University), Hyderabad, Telangana. He also shared his knowledge at reputed LN Mishra College of Business Management, Muzaffarpur (Bihar).

He has completed his B.Sc. (Hons) in Statistics from Aligarh Muslim University (AMU), Aligarh. He did Master of Business Administration (MBA) from Faculty of Management Studies and Research (FMSR), L.N.M.I. Patna with specialization in Marketing \& also got Master of Business Administration (MBA) degree with specialization in Agriculture Business. He has qualified UGC-NET in Management. He has completed his Ph.D. in Management from Jamia Millia Islamia (JMI), New Delhi. He did a short term certificate course in Soft Skill from IIT, Roorkee.

His area of research is CRM, Rural Marketing, Research Methodology, Sales \& Advertising Management.

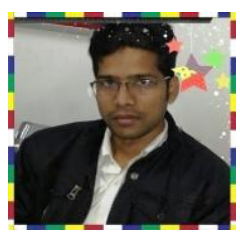

Naiyar Iqbal is currently doing Doctor of Philosophy ${ }^{\circ}$ Ph.D. (Computer Science) and he has also received his Master of Technology ${ }^{\circ}$ M.Tech. (Computer Science) degree from Department of Computer Science and Information Technology, Maulana Azad National Urdu University (Central University), Hyderabad, Telangana. He has got his Diploma in Computer Applications ${ }^{\circ}$ (DCA) from National Council for Promotion of Urdu Language, New Delhi. He has also completed his Bachelor of Computer Applications ${ }^{\circ}$ (BCA) and Master of Computer Applications ${ }^{\circ}$ (MCA) degrees from Indira Gandhi National Open University (Central University), New Delhi.

He has four years experience in teaching at Under Graduate (UG) \& Post Graduate (PG) levels. His area of research is Data Mining, Machine Learning, Soft Computing, Artificial Intelligence, Bioinformatics. 